\title{
Dominance of older scientists 'threatens research' in India
}

New Delhi. The average age of scientists working for government scientific organizations in India is increasing at an alarming rate, according to a study carried out by the Department of Science and Technology (DST), which says that this should be a "matter of concern" to the government.

In particular, the study has found that about 80 per cent of scientists occupying senior positions are over 50 years of age. One-third of those in junior levels, and two-thirds of middle-level scientists, are also over 50 years old.

The study was carried out by $A$. $R$. Rajeswari of DST, and covered researchers in 10 agencies operating 247 research and development (R\&D) laboratories, employing 31,340 scientists. It found that almost half of the researchers joined their organizations before 1975 , and pointed out that they "need retraining to keep abreast of the latest developments in science and technology".

Unless action is taken, says the study, leaving the work of these institutions in the hands of older scientists may reduce the overall viability of Indian research. It says that the current situation is due to rigid employment structures and regulations governing appointments and promotions. For instance, "senior positions were invariably reached only by seniority measured in sheer number of years in an organization, rather than by merit promotions".

Sri Krishna Joshi, who recently retired as head of the Council of Scientific and industrial Research (CSIR), admits that the ageing of research personnel "has adversely affected the innovativeness and creativity of CSIR".

Joshi claims that the average age of CSIR scientists is "rather high" because a ban on recruitment has been in place for the past decade, as a result of a lack of resources. The ban was lifted only a few months ago.

The DST study has also highlighted the lopsided gender profile of India's scientific agencies. Of the 301 senior positions analysed, only two per cent were occupied by women.

While most male scientists belonged to the older age bracket, the majority of female scientists were younger (under 43), apparently because female entry into science is relatively recent.

The study also shows that India's women scientists may be more productive than their male counterparts: on average more patents are granted to female than to male researchers.

K. S. Jayaraman

\section{Money woes fail to weaken Japan's support for science}

Tokyo. Despite a continuing recession, as well as the need for massive government payments to bail out failing banks and housing and loan corporations, Japan's science-related ministries and agencies have managed to win surprisingly large increases in the budget for the 1996 fiscal year, which begins on 1 April.

Impoverished university researchers will fare particularly well. Not only is there a large increase in the grant budget of the Ministry of Education, Science, Sports and Culture (Monbusho), but there are also new grant schemes open to university researchers from the Ministry of International Trade and Industry (MITI) and the Science and Technology Agency (STA), marking a new era of cooperation between these agencies.

The total government budget of $¥ 75,105$ billion (US $\$ 750$ billion), an increase of 5.8 per cent over last year, was approved by the cabinet at the end of last month.

The budget must still be formally approved by the Diet, Japan's parliament. But science-related elements are rarely, if ever, changed in the approval process, although a controversial outlay of $¥ 685$ billion to bail out failing financial institutions may well delay approval by the Diet - and could even bring about a general election.

The comparatively large increases for science agencies, from 5 to 10 per cent, stand in sharp contrast to the fate of other government departments. The increase for overseas development assistance, for exam-

HIGHLIGHTS OF JAPAN'S BUDGET FOR SCIENCE FOR 1996 (in billion yen: US $\$ 1=100$ yen)

\section{$\%$ Change}

\section{Science and Technology Agency}

Total R \& D budget

Special promotion funds

Space

Nuclear power

Spring-8

Human Genome

Human Frontier Science Programme

Strategic basic research

692.8

21.5

177.9

319.5

16.7

2.4

3.6*

15.0

Ministry of International Trade and Industry

Total R \& D budget

319.0

Agency of Industrial Science

and Technology

Industrial scientific technology

Creative $R$ \& D projects

144.0

26.4

2.6 ple, will be only 3.5 per cent, and for defence only 2.6 per cent. Both have for many years tended to receive the largest increases.

Science and technology are now in favour, thanks to lobbying by a small group of comparatively young and powerful politicians from various parties who passed a law late last year requiring the government to do more to support basic research (see Nature 378, 227: 1995). The law does not commit the government to any specific increases. But it has given the science-related ministrics and agencies additional leverage in their budget negotiations with the Ministry of Finance.

Monbusho's competitive grant budget for university researchers has for the first time exceeded $¥ 100$ billion (US $\$ 1$ billion), representing an increase of more than 10 per cent, and in doing so, achieving an ambitious goal set by the ministry in 1992 when the grant budget stood at only 765 billion.

Also notable is a new grant scheme for 'strategic' research from the STA. With a budget of $¥ 15$ billion in its first year, this will provide five-year grants ranging in value from a few tens of millions of yen to $¥ 200$ million a year, and will be open to university researchers, as well as researchers in national research institutes. Similarly, MITI has a new programme for 'creative' research, with a budget of $¥ 2.6$ billion.

These grant schemes follow on from programmes introduced by MITI and STA in one-off supplementary budgets last year (see Nature 377, 378; 1995). They represent the first time government agencies other than Monbusho have been able to provide large grants to university researchers. STA's success in winning the full $¥ 15$ billion requested from the finance ministry is particularly remarkable; normally, such budget requests are trimmed in the end-of-year negotiations, and it is a sign of the new climate that STA obtained the full sum it was seeking .

In line with a recent call by the government to double the number of postdoctoral fellows in Japan to 10,000 by the end of this decade, Monbusho and STA have each won large increases for their postdoctoral fellowship schemes. Monbusho has also been awarded a substantial increase for its new Centre of Excellence (COE) programme, which provides large sums of money, including funds for postdoctoral fellows, for a few select groups of university researchers. David Swinbanks 